\title{
Algaba de Ronda, un laboratorio socioeconómico para la gestión colectiva del patrimonio
}

El proyecto Algaba de Ronda nace en el año 2002 como iniciativa empresarial de un grupo de personas de formación dispar para la gestión holística del patrimonio mediante fórmulas de cooperación y autoempleo que rompen la dicotomía público/privado aun sometida a las leyes del mercado y bajo las exigencias de la administración, abriendo los huecos necesarios de la economía social, ecológica y colaborativa. Para ello, hemos contado con un excelente recurso, la finca Algaba donde persisten masas boscosas con flora y fauna autóctonas, además de abundantes y variadas materias primas, factores que favorecen la práctica de la arqueología experimental, la educación ambiental y la agroecología, disciplinas en cuya perspectiva general convergen investigación, difusión y conservación del patrimonio histórico-natural y tutelan los procesos de gestión integral.

María Sánchez Elena | coordinadora del proyecto Algaba de Ronda ${ }^{1}$

URL de la contribución <http://www.iaph.es/revistaph/index.php/revistaph/article/view/4411>

Si nos centramos en el ámbito histórico o más concretamente prehistórico, las palabras de Sergio Mellado nos presentan el poblado de la Algaba de la siguiente forma: "ni la sevillana Itálica ni la gaditana Villa de Baelo Claudia. Ni siquiera el antiquísimo poblado de los Millares en Almería. El primer pueblo andaluz está en Ronda. $\mathrm{O}$ al menos una fiel y cuidada reproducción de los primeros asentamientos comunales de la humanidad fuera ya del refugio natural que proporcionaban las cuevas" (MELLADO, 2005). En este sentido, lo relevante y extraordinario es la construcción de una réplica de un poblado de la Prehistoria Reciente a partir de la arqueología experimental, con los diferentes contextos espaciales para la reproducción de los procesos productivos; por otro lado, toda la infraestructura logística y de apoyo que se ofrece a los investigadores interesados en desarrollar sus proyectos en él facilita entender y conocer las actividades artesanales, los procesos de trabajo y modos de vida practicados por las sociedades prehistóricas del sur de la Península Ibérica, en tanto formas de vida que han llegado hasta nuestro tiempo.

La compleja relación dialéctica que se establece entre la investigación y el uso de sus resultados para la socialización del conocimiento sobre la prehistoria ocupa un lugar central validando hipótesis y proponiendo usos correctos de los modelos explicativos e interpretativos propuestos.
En este sentido la difusión, con distintos niveles de elaboración adaptados a los diferentes públicos, constituye una estrategia cuyo objetivo no es sólo la generación de conocimiento, sino también comunicar y exponer las técnicas de trabajo, los procesos artesanales vinculados con formas de vida, partiendo siempre del ideal de innovación pedagógica y nuevas estrategias de comunicación y participación.

Desde el ámbito de la Agroecología, la finca Algaba es un espacio biogeográfico, cultural, educativo, económico y arraigadamente social, en el que a partir de propuestas de cooperación e innovación rural, se investiga para encontrar respuestas factibles que contribuyan al desarrollo sostenible y medioambiental de las explotaciones ganaderas y agrícolas de la Serranía de Ronda y, en concreto, toma como reto principal la recuperación de razas ganaderas en peligro de extinción. Así, el desempeño realizado durante más de 10 años desde la cooperativa Algaba de Ronda se traduce en resultados meritorios pero aun incipientes, porque para afianzar este necesario proyecto patrimonial, a la vez que genético y medioambiental, se precisa la implicación ineludible y urgente del conjunto de agentes sociales, científicos y políticos.

Tras estos dos ámbitos de trabajo vemos a la Algaba con toda la profundidad que recoge su etimología árabe 


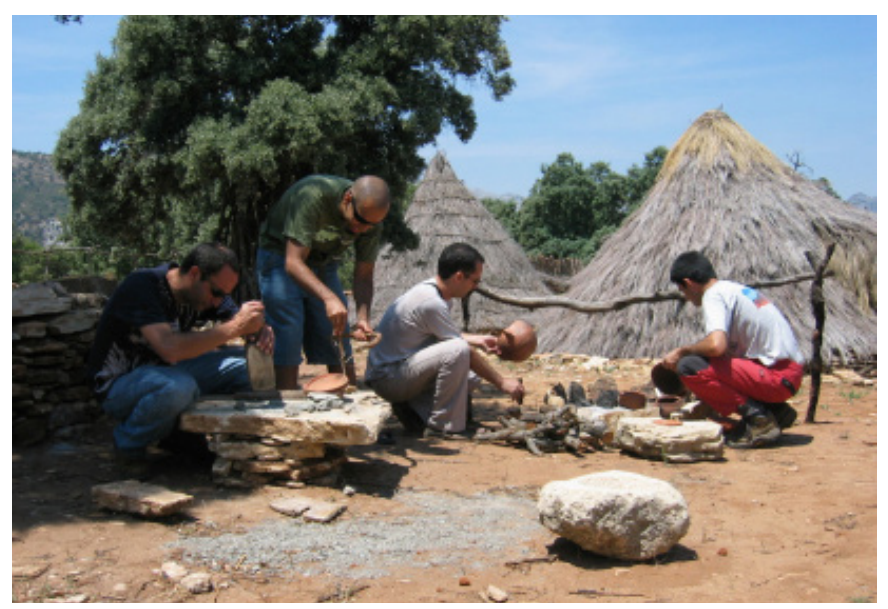

fotos Algaba de Ronda

y que refiere la idea de oasis, un precioso bosque de encinas, quejigos y alcornoques, a tan sólo cuatro kilómetros al sur de la ciudad de Ronda en su rumbo hacia el Valle del Genal, acurrucada entre las hermosas crestas calizas que, como a la propia ciudad, se prestan para arroparla y conferirle la singularidad paisajística que la caracteriza. No en vano en las proximidades de Algaba convergen los parques naturales Sierra de las Nieves y Sierra de Grazalema, así como sendas reservas de la biosfera. Toda esta riqueza mantiene su función como centro de educación ambiental con distintos recursos de carácter educativo y vivencial que son fruto de reconocidos y premiados procesos de investigación y documentación propia: un observatorio ornitológico, un área de interpretación de la geología de la Serranía de Ronda, especialmente del monte mediterráneo y su biodiversidad.

Si hasta ahora hemos conocido el qué y dónde de la iniciativa ahora es necesario poner en valor el cómo y quién, subrayando que Algaba de Ronda ${ }^{2}$ nace sobre todo como un proyecto de mujeres unidas por la ilusión de crear un espacio de encuentro, conocimiento y reflexión en torno a los valores patrimoniales del mundo rural. Un proyecto fraguado tras años de reflexión y audacia, a lo que hubo que sumar grandes dosis de tesón, trabajo y capacidad de gestión, para romper los techos de una sociedad que no contribuye en su justa medida a la solvencia de las comunidades rurales por lo que, mas allá de la dicotomía público-privado, los nuevos modelos

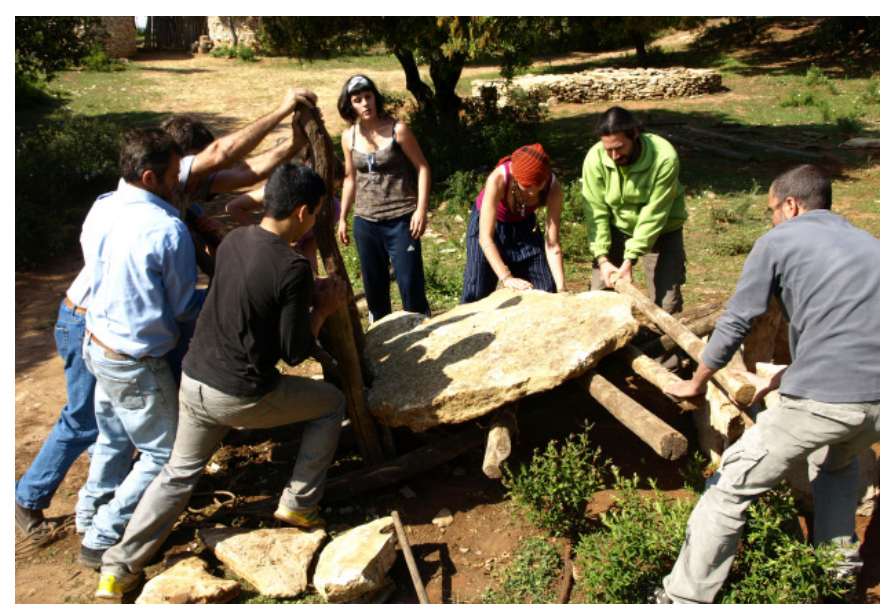

de éxito apuntan a que la solución está en crear redes de economía social y, en este caso, ha contado con la participación de más de 10 pequeñas empresas locales, varias asociaciones y 5 universidades andaluzas.

\section{NOTAS}

1. Este proyecto fue uno de los presentados en el primer encuentro de Redactívate del IAPH. Más información en $<$ www.iaph.es/web/canales/formacion/cursos/Redactivate/> y <www.iaph.es/revistaph/index.php/revistaph/ article/view/4356>

\section{Más info: <www.algabaderonda.com>}

\section{BIBLIOGRAFÍA}

- MELLADO, S. (2005) El primer pueblo andaluz está en Ronda. El País [en línea], 2 de abril de $2005<$ https://elpais. com/diario/2005/04/02/andalucia/1112394161_850215.html> [Consulta: 26/06/2019] 